\title{
Indian Academy of Pediatrics Guidelines on School Reopening, Remote Learning and Curriculum in and After the COVID-19 Pandemic
}

\author{
Swati Ghate, ${ }^{1}$ Bakul Jayant Parekh,,${ }^{2}$ Rajeev Kumar Thapar, ${ }^{3}$ PR Nadkarni, ${ }^{4}$ Santanu Sen,,${ }^{5}$ Utkarsh \\ Bansal, ${ }^{6}$ ChHaya Harnarain Sambhariya, ${ }^{7}$ Swati Popat, 8 Piyali Bhattacharya, 9 Sushma Kirtani, ${ }^{80}$ \\ Yashwant Kanetkar, ${ }^{11}$ Swati Popat Vats, ${ }^{12}$ SS Kamath, ${ }^{13}$ Manu RaJ, ${ }^{14}$ GV Basavaraja ${ }^{15}$ And PiYuSh GuPta ${ }^{16}$ \\ From ${ }^{1}$ Babylon's Newton Child Development and Support Centre, Jaipur; ${ }^{2}$ Bakul Parekh Hospital for Children, Mumbai; \\ ${ }^{3}$ Department of Pediatrics, Rama Medical College Hospital and Research Center, Hapur, UP; ${ }^{4}$ Manipal Academy of Health and \\ Education, Panjim, Goa; ${ }^{5}$ Kokilaben Dhirubhai Ambani Hospital, Mumbai; ${ }^{6}$ Department of Pediatrics, Hind Institute of Medical \\ Sciences , Barabanki, ${ }^{7}$ Asha Child Care and Developmental Clinic, Chandigarh; ${ }^{8}$ Om Pediatric Multispeciality Hospital, Rajkot; \\ ${ }^{9}$ Sanjay Gandhi Postgraduate Institute, Lucknow; ${ }^{10}$ Consultant Pediatrician, Dr Sushma Newborn, Child, Adolescent Clinic, \\ Panjim, Goa; ${ }^{11}$ Kanetkar Institute of Computing and Information Technology, Nagpur; ${ }^{12}$ Podar Education Network, Mumbai; \\ ${ }^{13}$ Indira Gandhi Cooperative Hospital, Kochi, Kerala; ${ }^{14}$ Amrita Institute of Medical Sciences and Research Centre, Kochi, Kerala; \\ ${ }^{15}$ Indira Gandhi Institute of Child Health, Bengaluru, Karnataka; and ${ }^{16}$ Department of Pediatrics, University College of Medical \\ Sciences and GTB Hospital, Delhi; India. \\ Correspondence to: Dr Piyush Gupta, Professor and Head, Department of Pediatrics, University College of Medical Sciences and \\ GTB Hospital, Delhi, India. prof.piyush.gupta@gmail.com
}

\begin{abstract}
Justification: With the unprecedented COVID-19 pandemic and the resultant school closure, children all over the country are undergoing a lot of educational, psychosocial, and physical problems. There is an urgent and deep felt need to offer scientific and concrete guidance for these concerns and support children in their educational development during these testing times. Objectives: To review the guidelines and recommendations given by various international agencies and formulate guidelines in the Indian context on (a) how and when to reopen the schools; $(b)$ ways and means of remote learning; and $(c)$ to identify the contents of curriculum that need restructuring in context of the current situation. Process: Indian Academy of Pediatrics (IAP) formed a task force of pediatricians, educationists and technological experts who connected through various video and social platforms. They gathered and exchanged information and thoughts. The writing committee drafted the guidelines and got approval of all the members of the task force. Recommendations: Schools can be reopened only when the local epidemiological parameters are favorable, the administration is equipped with adequate infrastructure and health care facilities, and the stakeholders (teachers, students, parents, and support staff) are prepared for the new normal. In the meanwhile, remote learning (media-based and /or otherwise) should reach to the last student to maintain uninterrupted education. The curriculum needs to be revised, with focus on revision and core contents. Informal learning of psychosocial empowerment and daily living skills should be encouraged rather than stressful formal learning.
\end{abstract}

Keywords: Education, Distance learning, e-learning, Lock down, Screen time.

$\mathrm{N}$ early 240 million school going students in India are homebound owing to the coronavirus disease 2019 (COVID-19) pandemic [1]. The loss in learning in pandemic is estimated to be up to $50 \%$ of the expected academic level [2]. The impact could be life long and likely to be most significant for the disadvantaged and marginalized children [3].

Schools provide a safe and stimulating environment to children for learning, education, physical activities, socialization, and cater to their nutritional needs through mid-day meal program. UNICEF's 'Lives Upended' report describes the consequences of the pandemic on nearly 600 million children in South Asia, including India [4]. School closure has resulted in stress among the children and their families and they are more likely to suffer from anxiety, depression and post-traumatic stress disorder during and after COVID-19 epidemic [5-7].

As of now, there is a lot of uncertainty and confusion about when and how to start the schools, in all sectors of the stakeholders including the government, school authorities, teachers, parents and the civil society. Efforts to continue education through remote learning are falling short in reach [8] and academic outcome, and children are also missing the socialization, which schools entailed [9]. Additionally, online learning is proving to be a big challenge for many. School closure has initiated the concept of digital remote learning, which is being popularized extensively, with due credit to the digital technology. However, it is now being realized that online 
learning is causing a lot of stress to the children and families [10].

Academics has always been a big burden for the Indian children [11]. They are occupied for one third of their day in the school and related academic activities. Schoolwork generates negative emotional states like low mood, low motivation, feeling of compulsion and anxiety [12]. The National Education Policy of Government of India, 2020, emphasises on the holistic development of children. It recommends easing out the academic stress and incorporating co-curricular activities in the mainstream education [13]. Children are placed at the centre of Sustainable Developmental Goals [14,15]. Being the advocate of holistic health of children and adolescents, the Indian Academy of Pediatrics tried to address these issues with a scientific and evidence-based temper.

\section{OBJECTIVES}

These guidelines are framed with the following objectives:

1. To recommend how and when the schools can be safely opened

2. To describe various ways and means of remote learning

3. To define appropriate contents of learning for students in the current times

\section{PROCESS}

The Indian Academy of Pediatrics, in June, 2020, constituted a task force on 'School reopening and remote learning' to address the issues outlined above. The members comprised of practicing pediatricians, teaching faculty, developmental and behavioural experts, epidemiologists, educationists, and technology experts. The members of the task force remained in touch tele- phonically, via emails and through social networking sites. Regular meetings were held periodically on video networking platform, the first being held on 21 June, 2020. Taking into consideration, the pressing need of the time, the issue of 'when to reopen the schools' was urgently addressed by the task force. The interim guidelines on the same were released and disseminated to the concerned authorities on 4 July, 2020 [16].

The members were divided into four subgroups to address four subsets of the objectives viz $(i)$ when is it safe to open the schools, (ii) how should the schools reopen safely, (iii) ways and means of remote learning during the school closure and (iv) contents of learning in the current times.

Review of literature was conducted by the members and they shared in their subgroups relevant scientific material and research studies obtained from various authentic sources. The main areas addressed were: $(i)$ epidemiology of COVID-19, (ii) clinical presentation and transmission of COVID-19 in children, (iii) effect of non-pharmacological measures in mitigating the transmission of Corona virus, $(i v)$ psychosocial impact of pandemic and school closure on children, $(v)$ ways and means to reduce the stress and (vi) various modes of distant education.

School opening Guidelines given by the World Health Organization (WHO), United Nations Children Fund, Centers for Disease Control and Prevention (CDC), and American Academy of Pediatrics (AAP), were thoroughly studied. PRAGYATA guidelines (on remote learning) by the Government of India, as well as guidelines from various educational boards of national significance were searched and studied. A pan-India survey was conducted to get inputs from the parents and teachers regarding their perspective on different aspects of school closure [10].

\section{Box I Principles to Guide the Formulation of School-reopening Guidelines}

- A total redressal of the education system is the need of the present crisis. However, physical and psychosocial health of children is more important than formal learning.

- School reopening should be based on the local epidemiological indices at the district level, the administrative preparedness to handle the consequences, if any, the school preparedness, the compliance of the society to the new physical hygiene norms and the parental willingness to send the children to school.

- All efforts should be made to retain the connect of students with the educational system, while the schools are closed. Various modes of remote learning should be blended to reach till the last student.

- Education should be stress free, meaningful and empowering for the present and future adversities.

- Relevant infrastructural changes in the education system, including manpower recruitment and training, need to be urgently addressed. 
Among the members, a leader was assigned for each subgroup. S/he collected all the inputs from other members and drafted their part of the guidelines. This draft was circulated in the subgroup inviting opinions and suggestions from other members. Accordingly, all four parts of the guidelines were redrafted by the respective subgroups. All the four parts of the guidelines were then collected and compiled together. These guidelines were then e-mailed to the members of the task force for critical comments. All the comments and suggestions were reviewed and incorporated in the guidelines. Differences of opinion were sorted out by re-referring the scientific studies and consulting experts from the concerned field. These redrafted guidelines were circulated to all the members. A virtual meeting of all the task force members was organised for final discussion. Consensus on all the points was reached by discussion. The final draft of guidelines was written. This final version was circulated to all the members by mail and everyone approved of it.

The task force agreed upon the following guiding principles (Box 1) based on the framework for reopening the schools, jointly given by UNESCO, United Nations Children Fund, World Bank and World Food Programme in June, $2020[17,18]$. The framework of the guidelines is depicted in Fig. 1.

\section{GUIDELINES}

\section{A. When to Reopen the Schools}

It has been amply demonstrated by various studies that COVID-19 poses very low risk to the physical health of the children as compared to adults [19]. Many studies are showing that children remain asymptomatic but carry significant viral load and can potentially spread COVID19 in the general population [20]. Hence, school reopening needs to be considered with utmost care $[17,21]$. Looking at the diverse sociocultural conditions and varying COVID-19 epidemiology across India, decision about opening of schools should be taken by the local authorities at the district level [22,23], and not at the national or state level. The following

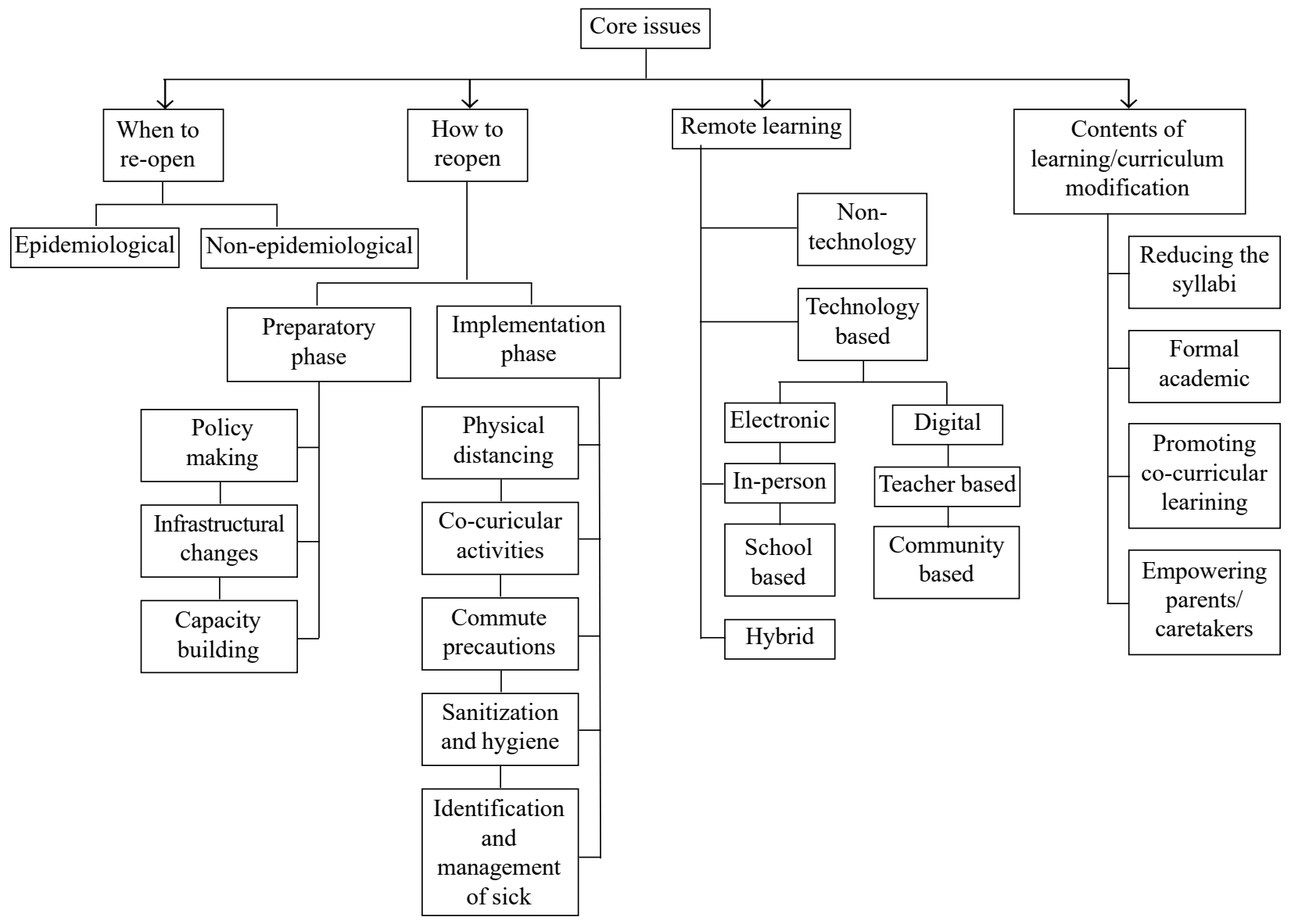

Fig. 1 Framework for IAP-school reporting guidelines. 
epidemiological parameters should be met with in the district, before the administration declares reopening of the schools [18,24]:

- The number of new cases of COVID-19 detected in the district should be steadily decreasing for the preceding two weeks.

- The case positivity rate should be less than 5 (that is, less than $5 \%$ of the total COVID-19 tests performed in the district per day turn out to be positive) for the preceding two weeks $[25,26]$.

- The number of new cases in the district per lakh population per day should be less than 20 in past two weeks.

Schools should be ready with the new norms of the infrastructure, training of the staff and health and hygiene facilities. Schools should have sorted out their timetable, and distributed the students in shifts to facilitate physical distancing [27]. An alliance should have been established between the schools and the local administrative and health authorities to guide, help and support the school staff [28]. The health department should be adequately equipped with enough testing capacity $(75 \% ; 59-87 \%$ as per the reference study, of the symptomatic contacts to mitigate a second wave), contact tracing, isolation, hospital beds and facilities to fight any eventuality [29].

The awareness drive on physical distancing, masks and sanitization should be ongoing and effective with citizens adequately adhering to these norms. The transport system should be functional. All the aforementioned conditions should be scrupulously reviewed periodically (every two weeks), and the decision to continue the physical schooling should be redressed.

\section{B. How to Reopen the Schools}

As per WHO, the school reopening should be undertaken in a stepwise manner starting with policy making, infrastructural changes and manpower training. The process has to be individualized for every school [28,30,31]. Standard operating protocols (SOP) should be in place before the school reopens [32].

\section{Preparatory Phase (before the students are called)}

Policy making: The school administration should designate responsible staff member(s) to define and execute standard operating protocols, keeping in tandem with the local administration guidelines. The policy should mandatorily include redressing the curriculum, curtailing the school hours, staggering the students and disinfection and hygiene protocols. The school reopen- ing should mainly aim for school connectedness, psychosocial well-being and stress-free learning of the children. Adequate staff including a counsellor and a medical nurse should be recruited. Staff above 60 and those with co-morbidities should be adjusted in work from home mode. The policy of 'Staying home if not well' should be in place for everyone.

Infrastructural changes:

- The entire school premises should be thoroughly cleaned and sanitised. New hygiene rules should be displayed in pictorial and child friendly manner in the premises.

- All the rooms including classrooms, staff rooms, libraries etc. should be airy and well ventilated. Furniture should be arranged with adequate spacing. Reception area should preferably have plexiglass guards.

- Toilet facilities and free flowing potable water should be made amply available.

- A sick room should be identified and kept ready with basic medicines and personal protection equipment.

Capacity building of staff, parents and students: Authentic scientific information regarding COVID-19 (symptoms, physical distancing, proper wearing of a mask, hand sanitization, coughing and sneezing etiquettes, and refraining from touching eyes, nose, mouth and face) should be shared with all staff members and parents and students using mails, telephonic calls, letters, pamphlets etc. All should be well informed about the new standard operating protocols.

The schools should encourage completing the routine vaccination of children and taking influenza vaccine for the staff members and the students. Those suffering from chronic illnesses like diabetes, asthma etc. and those on regular medications should be advised to consult their physicians before resuming the school.

It should be made clear to the staff and teachers that school reopening is mainly for school connectedness, psychosocial well- being and stress-free learning of the children. Schools should try to imbibe a sense of social responsibility required in Covid times, among its staff, parents and students.

\section{Implementing Phase}

Measures for physical distancing in classroom and beyond:

- School should open in batches with older students joining first. The students should be divided and 
called in different batches, in different shifts / alternate days and in staggered times.

- The classrooms should be kept ventilated by opening the doors and windows and air conditioners should be put off. Outdoor spaces like school ground should preferably be utilised to conduct classes.

- A distance of at least 1 meter should be strictly maintained between any two individuals in the school premises. Mingling should be permitted only among the small groups of selected individuals (Bubble class or cohorting). School gates, assemblies, corridors, toilets, libraries, gyms, locker rooms etc. and break times should be strictly monitored to avoid overcrowding.

- Children should bring minimal commodities like stationary, wrist watches, mobiles etc. and be discouraged from sharing the same. Eating during school hours and sharing food/water should be discouraged. Money transfer in lieu of mid-day meal is advisable.

- Visitors should be restricted. Communication with parents should be carried out digitally/postally.

Co-curricular activities: Group activities and team sports, National Cadet Corps (NCC), scouts, cultural and scientific meets etc. should be discouraged. Individually played non-contact games like badminton, athletics etc. and art activities like drawing, painting, dancing, may be allowed ensuring all safety precautions. Swimming pools should not be opened. Vocal singing, flute, mouth organ etc should be discouraged.

Precautions during commute: Respiratory, hand hygiene and physical distancing measures should be adhered during the commute. School buses should be disinfected after every trip, before picking up the new batch of students. The driver and the staff should wear masks and face shields. They should not belong to the high-risk category for COVID-19. Drop and pick up in personal vehicles by parents (and not by elderly/ co morbid care takers) should be encouraged. For older students, bicycles should be encouraged.

\section{Maintaining sanitation and hygiene:}

- School buildings and classrooms, gyms, sports centres, toilets etc. should be cleaned and sanitised at regular intervals and in between the two shifts. Places of frequent hand touch like door knobs, desks, benches, switches etc. should be disinfected repeatedly. A record of these activities should be maintained.

- Foot-operated hand sanitisation equipment with $70 \%$ alcohol-based sanitizer, foot-operated covered dust beans, soap, water, masks of suitable sizes etc. should be available appropriately and freely, at various places like classrooms, toilets, gyms, sports centres etc. Students and staff should be encouraged to use them frequently.

- Three layered cotton masks should be compulsory for all students, teachers, all school employees and visitors. Mask donning and doping and other mask manners should be thoroughly taught to all staff members and students. Children below five should be assisted and watched carefully (for breathing difficulties) while using mask.

- Spitting should be strictly banned and signage for the same displayed.

\section{Screening and management of the sick:}

- Those with body temperature raised beyond $37.3^{\circ} \mathrm{C}$ or $99.4^{0} \mathrm{~F}$ or those who report a history of fever or 'feeling feverish' in the previous 24 hours, should be denied entry in the school and referred for medical care. If some student or employee falls ill during schooltime, he/she should be isolated in the sick room having support staff equipped with adequate PPE.

- The testing for COVID-19 should be undertaken in every suspected individual who has attended the school, like one who is suffering from the classical symptoms of fever, cough and breathlessness, a close contact of a positive case, or fitting into any other criteria as per the norms laid down by the local health authority.

- Should a student/staff/visitor be positive SARS-CoV2 , the government authorities should be informed, and (s)he be asked to stay away from school for at least 14 days. Resuming the school should necessitate a fitness certificate from a registered practitioner.

- The school officials should extend full cooperation to the Government protocols like contact tracing, testing, isolation, disinfection etc.

- The school authorities should be liberal and considerate about absenteeism and leaves of their staff and students during Covid times.

- Discrimination against SARS-COV-2 positive staff/ students should be discouraged and they should be dealt with empathy.

\section{Remote Learning Guidelines}

Remote learning, or distant education [33], is a term used for the teaching-learning process wherein students are not 
in physical proximity of the teacher as against class-room setting and communicate using different means. The teacher-learner separation is by space or time, or both. Various types of media, both print and technology are used to maintain the communication [34]. Remote Learning could be technology-based or non-technology based. Technology based learning is offered through electronic media like radio and television, or through digital platform as in massive open online courses (MOOCs), group or individual digital classes or through (preloaded) gadgets. Non-technology-based learning is offered via print media as in correspondence education and external studies.

Depending on the availability of various technological resources (like radiofrequency penetration, DTH (direct to home)/cable connections, internet access) and that of gadgets (like radio set, mobile handset, TV set, computer, laptop, smartphone, preloaded tablets), technology based remote learning can be offered in several options. It could be asynchronous, wherein, a one-way communication from the teacher to the student takes place, or synchronous where learners can participate actively during remote learning [35].

Electronic technology-based learning makes use of basic phone, radio and television systems, and is predominantly asynchronous, whereas digital technology is internet or gadget dependent. Different types of modes using digital technology are either Interactive sessions (using online digital platforms, a virtual classroom with face to face interaction between the teacher and the students, the synchronous learning) or One-way teaching (where pre-recorded sessions reach the students either by sharing the link or preloaded in a tablet, pen drive, social media etc. It could be video, audio message, power point presentation, document etc., the asynchronous learning).

PRAGYATA guidelines of Government of India, vividly describe the various ways of imparting distant education with the help of technology [36]. AAP recommendations on media time can be used to avoid overuse of on-screen teaching and pave a way for blended learning $[37,38]$. When remote learning is combined with in person learning, it is called hybrid learning.

UNESCO's distance learning strategies in response to COVID-19 school closures [42] and 'crisis-sensitive educational planning', emphasize that all ways and means should be implemented to maintain the continuity of education for each and every child, in the times of complete/partial school closure [39]. The World Bank in its guidance note or remote learning and COVID-19, states that the non- technology based remote learning modes are very beneficial in settings with limited access to technology [40]. Here, print media is used to deliver the contents either by post or other delivery services, and is very pertinent to India.

\section{Hybrid learning: Remote learning and In-Person Learning}

All types of remote learning methods should be blended with one another appropriately as and when feasible, to make the learning more adaptable to all types of learners, to break the monotony and to overcome the shortcomings of individual modes of learning. Some scope for in person learning should be always sought after, keeping into account, all safety measures. The guidelines and recommendations for various types of remote learning are listed in Box 2, Table I and Table II.

\section{Content of Learning in COVID Times}

This part showcases IAP's advocacy on the nature of formal as well as informal educational contents that should be prioritized for the children in these testing times. Various studies are pointing to the fact that pandemic is causing a lot of stress and psychosocial burden on the children and adolescents [41]. Hence, it is imperative that the academics this year, should be made as stress free as possible. Every attempt should be made

Table I Recommendations on Time Allotment for Screen-based Remote Learning

\begin{tabular}{lllllll}
\hline Standard/class & Pre-primary & $1-2$ & $3-5$ & $6-8$ & $9-10$ & $11-12$ \\
\hline Screen time per session (min/d) & 30 & 30 & 30 & $30-45$ & $30-45$ & $30-45$ \\
Maximum sessions per day & 1 & 2 & 2 & 3 & 4 & 4 \\
$\begin{array}{l}\text { Days/wk } \\
\text { Content }\end{array}$ & 3 & 3 & 5 & 5 & 5 & 6 \\
Curricular & - & & & & $75 \%$ & $75 \%$ \\
Co-curricular/general & $100 \%$ & $>25 \%$ & $25 \%$ & $50 \%$ & $25 \%$ & $25 \%$ \\
\hline
\end{tabular}

All values denote maximum recommended upper limits; presence of parents/adult supervisor is mandatory for pre-primary and those up to 2 nd grade; preferable for grade 3-5; and optional for older children; use a judicious mix of synchronous/asynchronous modes of learning; interactive learning is to be preferred. 


\section{Box II Guidelines for Remote Learning During the COVID-19 Pandemic}

\section{General guidelines}

1. The focus should be on developing skill sets such as 'learning to learn' and the curriculum should be adapted suitably.

2. Hybrid and synchronous options should be preferred as far as possible.

3. Special care should be taken to involve marginalized children in remote learning

4. The problems arising out of the new ways of learning should be looked for and dealt with timely.

Non-technology based remote learning

1. This should be mandatorily included in all schools, and for all classes even though the facilities of online classes are available.

2. Learning material should include books, worksheets, hand-outs and practical activity guides (with kits). They should be student friendly, attractive, and easy to follow.

3. These materials could be delivered to and (assignments collected) from the students by post, other delivery systems or could be collected and dropped by parents from the school, taking all the precautions of physical distancing. Teachers should similarly convey their feedback and provide further individualized guidance depending on the evaluation.

Technology-based remote learning

A. Electronic technology-based learning

1. Government should come up with exclusive channels on radio and television and with good bandwidth for smooth dissemination till the remotest places. Local cable networking services should be utilized.

2. Educationists and broadcasters should establish a fair alliance for carrying out the delivery.

3. All pre-recorded available resources in the form of audio, video lessons should be tapped and aligned to cover the curriculum.

4. Interactive telephonic calls or SMS should be used for easy communication and feedback.

5. This mode of learning could be used for a group of students residing in a close community, following all the physical distancing norms.

B. Digital technology-based learning

1. Teachers should be trained periodically and evaluated for delivering the academic contents online in an interesting manner.

2. It should be ensured that the students have access to suitable gadgets, they are supervised and helped in learning digitally. No child should be denied his/her right of education, or de-enrolled from the school, even if (s)he is unable to use this mode of learning.

3. The age-specific norms for duration of use of digital/screen-based media should be followed meticulously (Table I). Digital technology-based learning should always be blended with various other modalities.

4. A virtual help desk should be created for students/parents/teachers/school authorities, to enable two-way communication, for smooth implementation of the digital learning.

5. Cyber safety rules should be repeatedly taught to the students.

\section{Guidelines for in-person learning}

A. Teacher-based learning

- A teacher takes the responsibility of a group of students, like a mentor.

- The teacher selected for such a job should not be a high-risk person and should preferably be staying in the close vicinity of the allotted (10-15) students.

Continuted.. 
Box continued...

B. Community based learning: Mohalla schools

- A motivated willing educated adult should take this responsibility. Qualified youth, or elder students, preferably from the community should be oriented and assigned the job. A school like platform should be created and only a handful of students should be engaged for limited days/time in open spaces like parks, playgrounds etc. following all the safety precautions.

- The teaching-learning process could be carried out in person or using common media resources, public address systems, and digital equipment as feasible.

C. School-based learning

- Schools should provide an opportunity for the students to remain in touch with the teachers and promote school connectedness.

- With prior appointments, students/parents should be able to meet the teachers, following physical distancing norms, and sort out their problems.

- Exchange of learning materials/ assignments, library books should be carried over.

to keep the students connected to the educational system and to mitigate dropouts.

It appears prudent to involve the students in some-thing that is attractive and engaging yet enriching for them. Easing out on formal learning and emphasizing on informal co-curricular learning, is highly likely to prove to be a key to this. Students are more likely to find such contents of learning interesting and easy to follow through. This will increase their chances of continuing in the educational stream and reduce dropouts. The lessons learnt through the informal need-based learning will equip them with abilities to fight their current and future psychosocial issues. Empowering them with age appropriate daily life skills and vocational training, will go a long way in making them competent to face their future productively [43]. This is also in line with the National Education Policy, 2020, of Government of India [13].

\section{Reducing the Academic Burden of Formal Learning}

- The Educational Boards should undertake 50\% trimming of the syllabi for all the subjects of all the classes so that there is stress free and appropriate learning of the designated portion of syllabus while taking care that no part of the core contents of any subject of any class is deleted. The quantity and portion to be cut should be reviewed and readdressed from time to time.

- Revisiting and revising already covered portions from previous academic sessions should be aimed at to get a feeling of ease and accomplishment. New concepts should only be gradually introduced.

- Formal teaching learning should be restricted to graded subjects only, that is the languages, the mathematics and the science. Simple self-learning modules of other subjects should be made available to the students in the print form.

- All teaching should be child centred. Activity based participatory learning and observational learning should be promoted, rather than rote learning. It should stimulate thinking processes, should highlight applied aspects of the contents and give a sense practical utility.

- Due care should be taken to facilitate all types of learners like visual, auditory, tactile etc.

- The students should be evaluated intermittently so as to judge and improve the effectiveness of the new teaching-learning process.

\section{Recommendations for Imparting Formal Academic Content}

Pre-Primary (3-6 years): Teaching should be totally informal adapting play-way learning through rhymes, songs, dance, short stories, simple activities etc.

- Introduction to colours, shapes, animals, birds, day to day objects and their uses, pairing etc should be given.

- Reading should be introduced step wise after 4 years and pencil holding after 5 years of age. It should be limited to recognition and writing of alphabets and few small words/ two digits numbers.

- The students should be encouraged to assist their parents in the household work/kitchen work under their vigilant supervision. 
Table II Age and Stage Specific Guidelines on Suggested Contents of Technology Based Learning

\begin{tabular}{|c|c|}
\hline Age groups & Guidelines \\
\hline $3-6 y$ & $\begin{array}{l}\text { - Teacher- child connection: video chats, once in a week or fortnight } \\
\text { - Parent-child interaction- Co-viewing of activities like fun videos, games, phonics, } \\
\text { numbers etc. } \\
\text { - Children to watch and follow: yoga/play etc. (in the prescribed time limits), always co } \\
\text { viewed and facilitated by parents }\end{array}$ \\
\hline 7-8 y (Standards I-II) & $\begin{array}{l}\text { In addition to the above } \\
\text { - Introduce formal learning along with co- viewing and explanatory conversations. } \\
\text { - Parents' capacity building sessions to improve developmental skills and early literacy } \\
\text { skills in children in an activity-based manner. }\end{array}$ \\
\hline 9-11 y (Standards III to V) & $\begin{array}{l}\text { Co-viewing: desirable } \\
\text { - Introduce pre-recorded lessons on digital media followed by an interactive time with the } \\
\text { teachers. } \\
\text { - Promoting 'Learning to learn' through various modes of learning. } \\
\text { - Introducing cyber rules. } \\
\text { - Encourage to follow ergonomic practices }\end{array}$ \\
\hline 12-14 y (Standards VI to VIII) & $\begin{array}{l}\text { - Encourage independent learning } \\
\text { - Gradual introduction of new concepts } \\
\text { - Assignments: online plus paper pencil work }\end{array}$ \\
\hline $15-18$ y (Standards IX to XII) & $\begin{array}{l}\text { - Introducing newer modalities of remote learning: searching different search engines, } \\
\text { online submissions etc. } \\
\text { - Encouraging projects related to creative media use, equipping with nuances of technology } \\
\text { for wider use }\end{array}$ \\
\hline
\end{tabular}

Contents: 3-6 years: Play, story, rhymes, games, cartoons, creative art activities etc; 7-8 years: all the above and music, do it yourself activities, documentaries.

- Exposure to various home commodities, play items, art forms and to nature should be encouraged to promote learning thereof. Development of hand eye coordination and motor skills should be encouraged.

- Parents should actively talk and interact with children to empower them with language and communication skills.

Primary classes - Standards I to V:

- The focus should be to attract them towards formal learning environment and help develop age appropriate skill sets.

- Gross and fine motor skills should be encouraged through activities like play dough, beading, make and break toys etc.

- Early literacy and math skills should be introduced in an activity-based manner. Two letters word writing and calculation of numbers with two digits should be introduced and regular practice should be encouraged.

- Languages and mathematics should only be taught formally using simple colorful picture-based textbooks.

Upper primary-Standards VI to VIII:

- Independent learning should be promoted with emphasis on basic conceptual learning.

- Languages, mathematics and science should be included in formal education through practical/ activity-based approach.

- Basic linguistic skills like use of dictionaries, finding meaning of difficult words, antonyms, synonyms, understanding spellings and pronunciation should be taught in a child friendly manner. Similar strategies should be applied for science and mathematics.

- Regular small assignments should be given to maintain continuity in learning.

Secondary and senior secondary classes: Standards IX to XII :

- Self-dependence and responsible behaviour regarding schoolwork should be promoted in these 
senior students. SMART (specific, measurable, achievable, rewarding, time bound) goals should be given.

- They are at the crucial age and stage of learning, hence, hand holding as needed should be done meticulously to see them achieve their educational targets. Every effort should be made to see that they are prepared enough for the coming career formative years.

- The basic core concepts of the three subjects, languages, mathematics and science should be thoroughly undertaken in an online/hybrid/distant learning mode. The learning material should be thoughtfully divided into 'must know', 'need to know' and 'nice to know' topics and subtopics. Teaching should be ensured by priority to the must know portions, to begin with, and need to know, if feasible.

- Projects, models and activity-based submissions should be encouraged to get the practical touch to the knowledge. Literary reviews, essays, articles should be given as assignments.

- Research based work like collecting information from electronic or print media should be assigned.

- Small groups of students should be formed who could stay in touch with one another through gadgets (or in person following physical distancing norms), to help and motivate each other.

- The teachers should be contactable through audio, video calls, mails/e mails, or through interactive radio/TV platforms.

- Laboratories, libraries and in person teaching for practical classes, for tough topics and for solving difficulties could be arranged, following all physical distancing norms.

\section{Promoting Co-curricular Learning}

More emphasis should be given on imparting various cocurricular skills in age appropriate manner. This will make the children better equipped to face their present and future [44]. Other relevant topics could be added to the options in Box 3 and Fig. 2.

\section{Empowering the Caretakers}

Periodical training sessions of teachers and parents should address on how to help the children during the pandemic and how to identify children with psychological problems. Youth from the community should be trained in giving educational, psychosocial, informational and referral support to students and their families. They could act as one-point service resource for all Covid related daily life problems of the community.

\section{THE WAY FORWARD}

The Indian Academy of Pediatrics believes that the holistic and healthy development of children is fundamental for our nation's progress. The present guidelines on school reopening, remote learning and contents of learning are scientifically designed with an idea of helping children along with their caretakers and the society at large, especially keeping in mind the present unprecedented situation. We have tried our level best to answer most of the basic dilemmas related to education of children and the possible prejudices that may be present in the parents' minds given the current situation.

These guidelines are drafted with the sole purpose of helping the policymakers, school authorities, and other stakeholders to take appropriate and justifiable decisions. We have worked hard to ensure that these guidelines will be useful for ministries of central and state governments as well as district authorities to plan their course of action regarding school reopening. Educational boards and societies should also get guidance regarding contents and modes of teaching in the COVID-19 pandemic. The school authorities will find them immensely useful so as to take decisions while framing their new standard operating protocols. Teachers and parents will also get an understanding of how to help children in these testing times

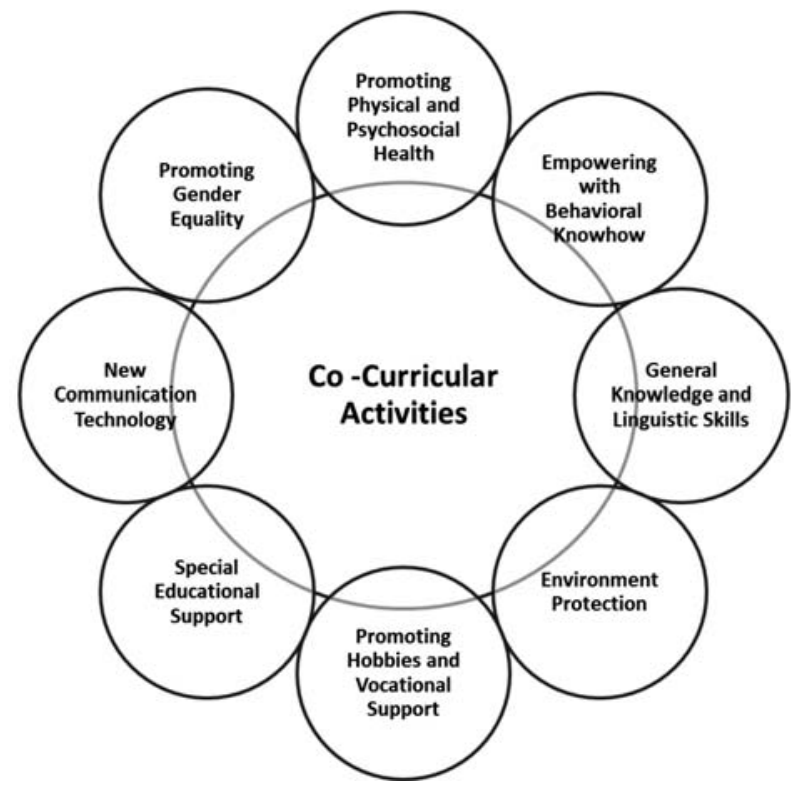

Fig. 2 Suggested co-curricular activities in the modified curriculum framework. 


\section{Box III List of Suggested Co-curricular Activities and Their Components}

Promoting physical health: Health and hygiene, nutrition, healthy lifestyle, COVID-19 related information, first aid, physical training etc.

Promoting psychosocial health: Life skill lessons, self-development, moral science, Social service, art appreciation, yoga, meditation, self -defence, indoor games, art and craft, reading biographies, self- help books

Empowering with behavioural knowhow: Age appropriate activities of daily living, basics of home science, economics, civic rules, road traffic rules, work experience, gardening

General knowledge: Encouraging reading newspaper, encyclopaedia, knowledge bank books etc., watching educational films, documentaries, channels etc

Word power and language building: Use of dictionaries, thesaurus, scrabbles, fictions, writing, learning new languages Environment protection: Awareness drives, best out of waste activities

Promoting hobbies: General reading, music, dance, drawing, painting, art and craft, poetry, story writing, mono acting and other indoor activities

Imparting vocational support: To adolescents, plumbing, carpentry etc

New communication technology: Practically oriented lessons, learning tools and apps (like play games, chess, number games on free websites), Cyber safety lessons and healthy media usage guidance

Gender equality: Sexuality education, Protection of children from sexual offence (POCSO) act

Development promoting tasks for pre-schoolers: Fine motor skills, Hand eye coordination, balancing etc

Special educational support for children with special needs: Individualised education plan for every child

IAP plans to distribute and disseminate the guidelines nationwide to all these stakeholders. The task force assigned with this job plans to review these guidelines after a period of six months. They will be re-addressed depending on the latest epidemiological conditions and the resultant feedback and gaps that may have been identified during the running of this program.

Contributors: All authors were part of the IAP Task Force on School Reopening and Remote learning that formulated these Guidelines. BJP, GVB, PG and SG: conceived the Guidelines, prepared the agenda, and executed administratively. PG: led the discussions and all the members actively participated. YK, SPV, PRN: contributed extensively on educational and technological angles of the guidelines. SSK and MN; guided on the epidemiological aspects. BJP, RKT, UB, PB, SS, SK, PN, SP, CHS and SG: reviewed the literature. UB, PG, PB, RKT and SG: worked on the survey to generate Indian data on the topic. RKT, PRN, SS, SP, CHS and SG: wrote the first draft of respective sections assigned to them. Review of literature and the first drafts were peer reviewed by PG, PB, SK, YK and SPV. PG, PB, SSK: provided intellectual inputs and overall guidance at every step. BJP, GVB, PG: provided the administrative support from the Indian Academy of Pediatrics and coordinated between the team and executive board members of the Academy. The final document was drafted by SG and RKT; and edited by PG. All authors approved the final recommendations of the guidelines.

Funding: None; Competing interest: None stated.

\section{REFERENCES}

1. Education Statistics at a Glance. Government of India: Ministry of Human Resource Development, Department of School Education and Literacy Statistics Division. 2018: p. 27. Table-7: Level-wise Enrolment in School \& Higher Education: 2015-16. Available from: https:// mhrd.gov.in/sites/upload_files/mhrd/files/statistics-new/ ESAG-2018.pdf. Accessed June 26, 2020.

2. Kuhfeld M, Soland J, Tarasawa B, Johnson A, Ruzek E, Liu J. Projecting the potential impacts of COVID-19 school closures on academic achievement. Edworkingpapers.com. 2020. DOI: https://doi.org/ 10.26300/cdrv-yw05

3. Policy Brief: The Impact of Covid-19 on Children. United Nations. 15 April 2020. Available from: https://www.un. org/sites/un2.un.org/files/policy_brief_on_covid_ impact_on_children_16_april_2020.pdf. Accessed September 5, 2020.

4. Lives Upended: How COVID-19 threatens the futures of 600 million South Asian children. UNICEF. June 2020. Available from: https://www.unicef.org/rosa/sites/ unicef.org.rosa/files/2020-06/UNICEF\%20Upended\% 20Lives\%20Report\%20-\%20June\%202020.pdf. Accessed September 5, 2020. 
5. Brooks S, Webster R, Smith L, et al. The psychological impact of quarantine and how to reduce it: rapid review of the evidence. The Lancet. 2020;395:912-20.

6. Galea S, Merchant RM, Lurie N. The mental health consequences of COVID-19 and physical distancing: The need for prevention and early intervention. JAMA Intern Med. 2020;180:817-18.

7. Loades M, Chatburn E, Higson-Sweeney N, et al. Rapid systematic review: the impact of social isolation and loneliness on the mental health of children and adolescents in the context of COVID-19. J Am Acad Child Adolescent Psychiatry. 2020; ;S0890-8567(20)30337-3.

8. Keelery S. Digital population across India as of January 2020. Statista. 2020. Available from: https://www. statista.com/statistics/309866/india-digital-population/. Accessed September 15, 2020.

9. Kumar A, Nayar K, Bhat L. Debate: COVID 19 and children in India. Child and Adolescent Mental Health. 2020;25:165-66.

10. Bansal U, Ghate S, Bhattacharya P, Thapar RK, Gupta P. Parental perspectives on remote learning and school reopening in COVID times. Indian Pediatr. 2020;57: 1177-78.

11. Jain G, Singhai M. Academic stress amongst students: a review of literature. Prestige e-Journal of Management and Research. 2017:4:58-67.

12. Verma S, Sharma D, Larson R. School stress in India: Effects on time and daily emotions. Int $\mathrm{J}$ Behav Dev. 2002;26:500-08.

13. National Education Policy 2020. Government of India: Ministry of Human Resource Development. Available from: http://niepid.nic.in/nep_2020.pdf. Accessed September 19, 2020.

14. Lark H, Coll-Seck A, Banerjee A, Peterson S, Dalglish S, Ameratunga S, et al. A future for the world's children? A WHO-UNICEF-Lancet Commission. The Lancet. 2020; 395:605-58.

15. Child Rights and the 2030 Agenda for Sustainable Development. United Nations Human Rights. 2020. Available from: https://sustainabledevelopment.un.org/ content/documents/26130Child_Rights_2030_Agenda_ HLPF 2020.pdf. Accessed September 15, 2020.

16. Interim IAP Guidelines on School Reopening (Part1), 4 July 2020. Available from: https://iapindia.org/pdf/1425INTERIM-IAP-GUIDELINES-ON-SCHOOL-REOPENING. $p d f$. Accessed September 15, 2020.

17. Framework for reopening schools. UNESCO. United Nations Children's Fund. World Bank. World Food Programme. June 2020. Available from: https://unesdoc. unesco.org/ark:/48223/pf0000373348. Accessed July 7, 2020.

18. Covid 19 planning considerations: Guidance for school reentry. AAP. 2020. Available from: https://services. aap.org/en/pages/2019-novel-coronavirus-covid-19infections/clinical-guidance/covid-19-planningconsiderations-return-to-in-person-education-in-schools. Accessed September 9, 2020.

19. Jiehao C, Jin X, Daojiong L, et al. A case series of children with 2019 novel coronavirus infection: clinical and epidemiological features. Clin Infect Dis. 2020;71: 1547-51.

20. Heald-Sargent T, Muller W, Zheng X, Rippe J, Patel A, Kociolek L. Age-related differences in nasopharyngeal severe acute respiratory syndrome Coronavirus 2 (SARSCoV-2) levels in patients with mild to moderate coronavirus disease 2019 (COVID-19). JAMA Pediatrics. 2020; 174:902.

21. John T, Dharmapalan D. When should schools be reopened? Free Press Journal. 16 September 2020. Available from: https://www.freepressjournal.in/analysis/ when-should-schools-be-reopened. Accessed September 20, 2020.

22. Coronavirus disease 2019 (COVID-19) in the EU/EEA and the UK - eleventh update, 10 August 2020. Stockholm: ECDC; 2020. Available from: https://www. ecdc. europa.eu/sites/default/files/documents/covid-19-rapidrisk-assessment-20200810.pdf. Accessed September 10, 2020.

23. Considerations for school-related public health measures in the context of COVID-19. WHO. 14 September 2020. Available from: https://www.who.int/publications/i/item/ considerations-for-school-related-public-healthmeasures-in-the-context-of-covid-19\%20\%EF\%BB\%BF. Accessed September 18, 2020.

24. Operating schools during COVID-19: CDC's Considerations. CDC. 1 September 2020. Available from: $h t t p s: / /$ www.cdc.gov/coronavirus/2019-ncov/community/schoolschildcare/schools.html. Accessed September 18, 2020.

25. Dowdy D, D'souza G. Covid-19 Testing. Understanding the percent positive. Johns Hopkins Bloomberg School Of Public Health. 10 August 2020. Available from: https:// www.jhsph.edu/covid-19/articles/covid-19-testing-under standing-the-percent-positive.html. Accessed September $10,2020$.

26. Indicators for dynamic school decision making. CDC. 15 September 2020. Available from: https://www.cdc.gov/ coronavirus/2019-ncov/community/schools-childcare/ indicators.html. Accessed September 18, 2020.

27. What will a return to school during the COVID-19 pandemic look like? UNICEF. 24 August 2020. Available from: https://www.unicef.org/coronavirus/what-willreturn-school-during-covid-19-pandemic-look. Accessed September 18, 2020.

28. Operating schools during COVID-19: CDC's considerations. CDC. 1 September 2020. Available from: https:/ /www.cdc.gov/coronavirus/2019-ncov/community/ schools-childcare/schools.html. Accessed September 18, 2020.

29. Panovska-Griffiths J, Kerr C, Stuart R, et al. Determining the optimal strategy for reopening schools, the impact of test and trace interventions, and the risk of occurrence of a second COVID-19 epidemic wave in the UK: a modelling study. The Lancet Child Adol Health. 2020. DOI: https:// doi.org/10.1016/S2352-4642(20)30250-9

30. Narmada S, Somasundaram A. Preparedness for reopening and conduct of schools during and post covid-19 period. Indian Journal of Practical Pediatrics.2020;22:217-22.

31. Covid 19 - Corona control guidelines for school and 
college reopening. IMA Kerala State branch. 13 May 2020. Available from: https://imakerala.com//uploads/imaguide linedoc/ 1591953319.pdf. Accessed July 18, 2020.

32. Framework for Opening Schools, United Nations, UNICEF, The World Bank, The World Food Program, April 2020. From: https://www.unicef.org/documents/ framework-reopening-schools. Accessed September 7, 2020.

33. Kiryakova G. Review of distance education. Trakia Journal of Sciences. 2009; 7:29-34.

34. Remote Learning, EdTech \& COVID-19. The World Bank. July 15, 2020. Available from: https://www. worldbank. org/en/topic/edutech/briefledtech-covid-19. Accessed August 16, 2020.

35. King F, Young M, Drivere-Richmond K, Schrader P. Defining distance learning and distance education. AACE Journal. 2001:91-14.

36. Pragyata Guidelines for Digital Education: Department of School Education and Literacy; Ministry of Human Resource and Development, GOI. 14 July 2020. Available from: https://www.mhrd.gov.in/sites/upload_files/mhrd/ files/pragyata-guidelines_0.pdf. Accessed on 16 August 2020.

37. Radesky J, Christakis D. Media and young minds. Pediatrics. 2016;138:e20162591.

38. Livingstone S. New 'Screen Time' Rules from the
American Academy of Pediatrics. Parenting for a Digital Future. 21 October 2016. Available from: https:// blogs.lse.ac.uk/parenting4digitalfuture/2016/10/21/newscreen-time-rules-from-the-american-academy-ofpediatrics/. Accessed Sep-tember 20, 2020.

39. Distant learning Solutions. UNESCO. 2020. Available from: https://en.unesco.org/covid19/ educationresponse/ solutions. Accessed September 10, 2020.

40. Guidance Note: Remote Learning \& COVID-19. World Bank. 7 April 2020. Available from: http://documents 1. worldbank.org/curated/en/531681585957264427/pdf/ Guidance-Note-on-Remote-Learning-and-COVID-19.pdf. Accessed September 10, 2020.

41. Ghosh R, Dubey M, Chatterjee S, Dubey S. Impact of COVID -19 on children: special focus on the psychosocial aspect. Minerva Pediatrica. 2020;72(3). DOI: https:// doi.org/10.23736/S0026-4946.20.05887-9.

42. Informal education. Wikipedia. Available from: https:// en.wikipedia.org/wiki/Informal_education\#Benefits. Accessed September 12, 2020.

43. Norqvist L, Leffler E. Learning in non-formal education: Is it "youthful" for youth in action? Int Rev Edu. 2017;63:235-56..

44. Rogoff B, Callanan M, Gutiérrez K, Erickson F. The organization of informal learning. Review of Research in Education. 2016;40:356-401. 